\title{
Consumo alimentar e disponibilidade de alimentos dos moradores da Ilha de
}

\section{Cotijuba no Bioma Amazônico}

\author{
${ }^{1}$ Thammy Rosy Nava de Oliveira SOUZA \\ ${ }^{2}$ Patrícia Miranda MENDES \\ ${ }^{3}$ Alexandre Augusto Pinheiro de OLIVEIRA

\begin{abstract}
${ }^{1}$ Graduada em Nutrição pelo Centro Universitário do Pará - CESUPA, Belém/PA. thammynavanutri@ hotmail.com
${ }^{2}$ Mestre em Planejamento do Desenvolvimento (PLADES) - Núcleo de Altos Estudos Amazônicos/UFPA. Docente do Curso de Bacharelado em Nutrição do Centro Universitário do Pará - CESUPA, Belém/PA e do curso de nutrição da Universidade Federal do Pará - UFPA pmendes@ufpa.br

${ }^{3}$ Graduado em Nutrição pelo Centro Universitário do Pará - CESUPA, Belém/PA.
\end{abstract}

Recebido em: 30/10/2012 - Aprovado em: 23/12/2012 - Disponibilizado em: 30/12/2012

RESUMO: Na Amazônia, existem poucos dados sobre as escolhas e hábitos alimentares de populações tradicionais, bem como suas implicações nutricionais, é bastante comum se evidenciar problemas de saúde, muitas vezes em decorrência da monotonia alimentar que se baseia em peixe, farinha e açaí, assim como pelas condições inadequadas de higiene e/ou a qualidade da água. A Ilha de Cotijuba na Amazônia foi considerada através de estudos como predominantemente rural com traços urbanos. A pesquisa teve por objetivo traçar o perfil socioeconômico e alimentar dos moradores da ilha. O estudo foi do tipo transversal descritivo, com a coleta de dados realizada através da aplicação de Questionário de Freqüência Alimentar e Questionário Sócio-Econômico no período de janeiro a março de 2011. Os resultados demonstraram que $60,2 \%$ das famílias possuem renda de até um salário mínimo por mês, 58,1\% realizam tratamento de água para o consumo. No consumo alimentar, 80,6\% consomem farinha de mandioca e 45,2\% charque, dentre as frutas destacam-se o açaí $(63,4 \%)$ e a manga $(66,7 \%)$. Na ilha a maioria dos moradores, apresenta renda baixa. Realizam o tratamento da água para o consumo, porém muitas vezes de maneira inadequada. Apresenta-se um alto consumo de charque e baixo de peixe, diferenciando das populações tradicionais. Verificou-se uma população de baixa renda e escolaridade, com o perfil alimentar diferenciado de outras comunidades, sendo a base da dieta com arroz, feijão, farinha de mandioca e charque, e complementada com pães, leite, café e frutas locais. A aquisição da maioria destes alimentos é feita principalmente através da compra.

Palavras-chave: Consumo alimentar. Perfil socioeconômico. Comunidades tradicionais. Amazônia. Ilha de Cotijuba

ABSTRACT: In the Amazon, there are few data on the choices and habits foods of traditional populations and their implications nutrition, it is quite common to highlight health problems, many times due to the monotony of food based on fish meal and acai, as well as by inadequate hygienic condition and/ or quality water Cotijuba Island in the amazon was considered through studies as predominaly rural with urban features. The aim of this study was to describe the socio demographic and food of the islanders. This study was a cross-sectional descriptive type with data collection performed by applying Food Frequency Questionnaire and Socioeconomic Questionnaire from January to March 2011. The results showed that $60,2 \%$ have income of up one minimum wage per month, $58,1 \%$ use water treatment for drinking. On food intake, consume $80,6 \%$ of cassava flour and dried beef 45,2\%, among the fruits stand out from the açaí $(63,4 \%)$ and mango $(66,7 \%)$. In the majority of island residents, has a low income. Designed to treat water for consumption, but often inappropriately. It presents a high consumption of beef jerky and low fish differing from traditional populations. There was a low-income and schooling, with different nutritional profile of other communities, being the basis of the diet with rice, beans, cassava flour and dried beff and supplemented with bread, milk, coffee and local fruits. The acquisition of most of these foods is done mainly through purchase.

Key-words: Food consumption. Socio demographic profile. Traditional communities. Amazon. Cotijuba Island.

\section{INTRODUÇÃO} prevalência das formas tradicionais de

No Brasil, é notório as mudanças no

padrão alimentar, seguidas de novos desnutrição.

desequilíbrios nutricionais, além da

Existem poucos dados sobre as escolhas e hábitos alimentares, bem como suas implicações nutricionais. Todavia, 
Murrieta (2001) entende que as escolhas alimentares são o resultado da interação dialética entre as estruturas habituais do cotidiano, considerando-se o que é biologicamente necessário, socialmente desejado, ecologicamente possível e historicamente assimilado, ou seja, é a relação entre os ciclos ecológicos dos recursos naturais, a dinâmica político-econômica dos mercados locais e regionais e as representações de classe e preferências individuais.

A Amazônia possui pouco estudos sobre o consumo alimentar das populações tradicionais. Desta forma, é desconhecida a sua importância nutricional para a vida das populações nativas da região.

Observando-se nas poucas pesquisas recentes (AGUIAR, 2006; FRAXE, PEREIRA e WITKOSKI, 2008; DIEGUES, 2001; CANTO, 2004; MURRIETA, 2001, MURRIETA， 2008; SILVA， 2007)， a alimentação das comunidades amazônicas provem de uma série de produtos oriundos da exploração agrícola rudimentar, pesca artesanal, criação doméstica, caça e extrativismo florestal, compra, entre outros. Alguns destes estudos têm objetivado não apenas conhecer a especificidade do modo de vida das populações tradicionais da Amazônia, mas, sobretudo, pela crescente necessidade de se criar possibilidades de melhorias nas condições de vida dessas populações, que convivem com sérios problemas sociais e de saúde, onde destacamse os problemas alimentares.

Esses problemas em comunidades tradicionais da Amazônia geralmente estão ligados as carências nutricionais, devido a base da alimentação ser proveniente principalmente de açaí, mandioca e peixe, o que ocasiona em uma monotonia alimentar, necessitando assim de uma adequação nutricional, além da questão higiênicosanitária dos alimentos e a qualidade da água. Vale ressaltar ainda a "modernização alimentar" (MURRIETA et al, 2008), que nas últimas décadas tem feito parte dos hábitos alimentares de populações tradicionais, com a introdução de alimentos industrializados.

A comunidade "tradicional" em estudo é a da Ilha de Cotijuba, Martins (2003) nos mostra através de suas pesquisas, que a ilha apresenta traços predominantemente rurais, sendo que, a maioria das pessoas que vivem nesta comunidade sobrevive de atividades como a agricultura e a pesca, porém apresenta também traços urbanos. Entretanto, se faz necessário o surgimento de novas pesquisas a fim de afirmar se tal realidade ainda se faz presente na ilha.

\section{MATERIAL E MÉTODOS}

O estudo foi do tipo transversal descritivo, tendo como universo de estudo 93 famílias da ilha de Cotijuba que é localizada no município de Belém - PA às margens da 
Bacia do Marajó e possui uma área com cerca de $60 \mathrm{~km}^{2}$.

O cálculo amostral foi realizado através do sub-programa Epitable do software Epi-Info (OMS, 2000). Para a obtenção do tamanho amostral foi considerado o número de residências da ilha igual a 2325 (FUNASA, 2010), precisão desejada de $\pm 10 \%$ e prevalência esperada igual a $50 \%$. Como resultado obteve-se, com nível de confiança de 95\%, uma amostra de 93 famílias.

A coleta de dados foi realizada através da aplicação de questionário socioeconômico já que estes possuem uma relação direta com a alimentação e saúde da família, entre as perguntas temos: renda, escolaridade, tipo de moradia, abastecimento de água. Também foi aplicado o questionário de frequência alimentar qualitativo, com o intuito de avaliar a dieta habitual das famílias bem como a disponibilidade de alimentos através da procedência com a utilização das variáveis: não adquire, compra, agricultura, pesca, extrativismo e criação doméstica. As entrevistas foram realizadas no período de janeiro a março de 2011.

As informações coletadas foram agrupadas em um banco de dados e sofreram tratamento através do Software Microsoft Excel 2007. A análise dos dados de consumo foi realizada com base no "Estudo de Validação do Questionário de Frequência de Consumo de Alimentos" proposto por SICHIERI (1998) o qual classifica os alimentos em três categorias de consumo: baixo, médio e elevado. A verificação da qualidade da dieta da população de Cotijuba foi realizada através da comparação com a alimentação recomendada pelo Ministério da Saúde (2008), com base nas Diretrizes Alimentares para a População Brasileira.

\section{RESULTADOS E DISCUSSÃO}

Perfil socioeconômico

Os resultados mais expressivos da condição socioeconômica de moradores da ilha de Cotijuba, que podem se visualizados na figura 1, revelam que, pouco mais da metade $(50,5 \%)$ dos moradores destina seus lixos à queima, porém sabe-se que a incineração gera ainda mais resíduos tóxicos, tornando-se uma ameaça significativa para a saúde pública e o ambiente. De acordo com relatos dos moradores entrevistados, a comunidade possui coleta pública de lixo, no entanto a maioria relatou que esta coleta não é regular, portanto fazem opção por queimá-lo, pois, segundo eles e observações em campo, o acúmulo do lixo nas ruas causa um mau odor e proliferação de larvas e insetos.

Destaca-se ainda, que $63,4 \%$ utilizam o poço para o consumo de água da família e $41,9 \%$ dos moradores não realiza tratamento desta água, fator este que pode vir a repercutir negativamente na saúde destas pessoas, pois segundo o Ministério da Saúde (2008) são comuns as diarreias causadas por agentes 
infecciosos transmitidos pelo consumo de água não-tratada.

Quando comparamos os dados desta pesquisa com um estudo realizado em 2007, também nesta localidade, notamos que a questão do lixo piorou visto que naquela época apenas $24 \%$ da população entrevistada tinha destino inadequado para seus dejetos. Já em relação a água houve uma certa melhora, pois $55 \%$ da população não faziam o tratamento da água. Estes fatos estão relacionados diretamente com o alto índice de doenças, como a diarréia que teve $38 \%$ de casos registrados nesta população (COSTA et $a l, 2007)$.

Figura 1 - Condição socioeconômica dos moradores de Cotijuba

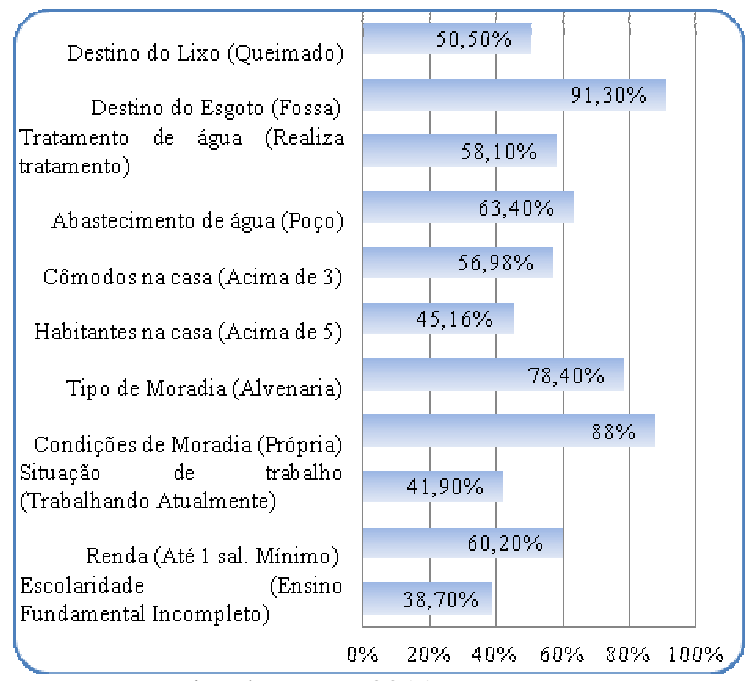

Fonte: Pesquisa de campo 2011

Quanto ao esgoto, a grande maioria $(91,3 \%)$ utiliza fossas fechadas. Em se tratando de moradia, $88 \%$ das famílias pesquisadas possuem casa própria, de alvenaria, sendo que a maioria das residências possuem mais de três cômodos $(56,98 \%)$ e abrigam mais de cinco pessoas $(45,16 \%)$.

Em relação à renda, se observou nos resultados da pesquisa, que a maioria das famílias estudadas $(60,2 \%)$ possui uma renda de até um salário mínimo. No que se refere ao emprego, apenas $41,9 \%$ dos entrevistados estão trabalhando atualmente o que pode influenciar para que a renda mensal do grupo familiar seja baixa, é importante ressaltar que foram encontrados $22,62 \%$ de aposentados.

A realidade da educação na ilha de Cotijuba demonstra que grande parcela dos entrevistados se encontra com ensino fundamental incompleto $(38,7 \%)$, porém encontramos também parcela expressiva de moradores que possuíam o ensino médio incompleto ou completo (36\%), esta baixa escolaridade pode contribuir para o desemprego e o nível de renda dos moradores da ilha.

\section{Consumo alimentar}

Os resultados sobre o consumo alimentar dos moradores da ilha de Cotijuba, estão sendo demonstrados na figura 2, cuja análise foi realizada utilizando os níveis baixo, médio e elevado consumo alimentar. Com relação aos alimentos industrializados, percebe-se uma maior porcentagem no nível elevado de consumo 38,7\%, já nos açúcares, doces, óleos e gorduras destacam-se um nível baixo de consumo com $73,1 \%$.

Em se tratando de leite e seus derivados, percebe-se que a maioria dos 
moradores pesquisados $(60,2 \%)$ possui um consumo elevado.

Figura 2 - Nível do consumo alimentar dos moradores de Cotijuba

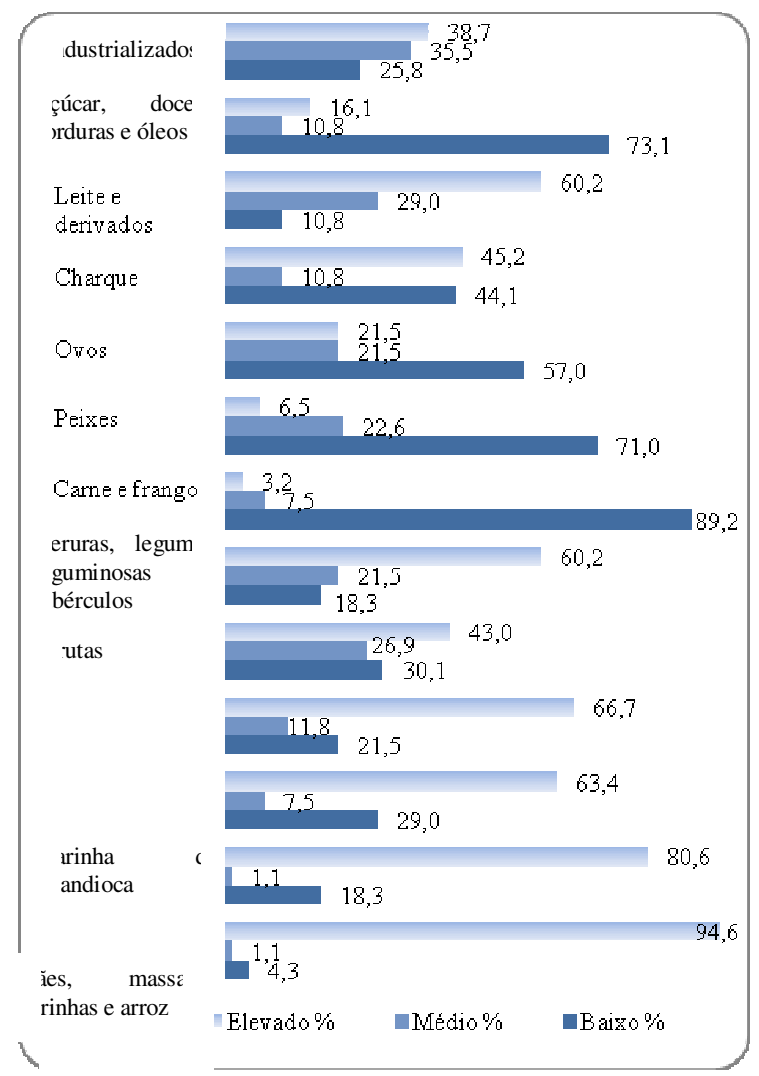

Fonte: Pesquisa de campo 2011

As proteínas de origem animal como ovos, peixes, carnes e frangos, se destacam por apresentarem nível baixo de consumo. Já o charque apresentou um percentual de $45,2 \%$ de nível elevado de consumo.

Os moradores pesquisados demonstraram ainda, que a maioria $(60,2 \%)$ apresenta um nível elevado de consumo de legumes, verduras e leguminosas, bem como $43 \%$ dos pesquisados apresentam um nível elevado de consumo de frutas. Com relação às frutas destacam-se a manga e o açaí que apresentam níveis elevados de consumo com $66,7 \%$ e $63,4 \%$ respectivamente.

No grupo dos pães, massas, farinhas e arroz observa-se um elevado consumo desses alimentos com 94,6\%. Deste grupo acentua-se a farinha de mandioca que apresentou $80,6 \%$ de nível elevado de consumo.

Murrieta et al (2008), no estudo de populações ribeirinhas em ecossistemas amazônicos, perceberam que a dieta é estruturada, predominantemente, sobre o consumo de peixe e farinha de mandioca. Em seguida vem o açaí (predominante nos ecossistemas paraenses) e o açúcar com importante representatividade de consumo, logo após os cereais (trigo, aveia e derivados) e por fim a segunda fonte energética animal mais relevante foi o leite. Na ilha de Cotijuba existe uma maior variedade de consumo de alimentos quando comparada a estas outras comunidades, mas é importante destacar que, em relação à fonte proteica animal, o peixe apresentou um consumo baixo e por outro lado o charque apresentou um consumo elevado.

Segundo relatos de moradores da ilha de Cotijuba, este baixo consumo de peixe se dá pelo custo elevado do mesmo, seguido de um baixo poder aquisitivo, o que foi evidenciado nos dados socioeconômicos. Através das observações em campo, notou-se ainda a presença pouco marcante de pescadores na ilha, fazendo com que o peixe 
venha de outros locais, tornando-se mais oneroso.

A base da dieta local é composta por arroz, feijão, farinha de mandioca e charque, sendo complementada por pães, leite, café e frutas locais (principalmente a manga e o açaí). Observou-se ainda um alto consumo de temperos naturais como a cebolinha, o coentro, a pimentinha verde e o tomate.

O Ministério da Saúde recomenda o consumo de alimentos ricos em carboidratos complexos, como cereais, de preferência integrais, tubérculos e raízes, para garantir $45 \%$ a $65 \%$ da energia total diária da alimentação (BRASIL, 2008). Em Cotijuba percebe-se um consumo adequado destes alimentos (arroz, farinha de mandioca e pães) com base nestas recomendações.

O consumo mínimo recomendado de frutas, legumes e verduras é de 400 gramas/dia para garantir $9 \%$ a $12 \%$ da energia diária consumida, considerando uma dieta de $2.000 \mathrm{kcal}$ (BRASIL, 2008). Em Cotijuba há, em média, um consumo elevado desses grupos de alimentos, garantindo dessa forma uma boa ingestão de vitaminas, minerais e fibras. Porém, com relação às frutas, essa ingestão é garantida principalmente na época de safra das mesmas. Vale lembrar que devido à variedade de frutas e suas safras, provavelmente sempre haverá um ou dois tipos de frutas disponíveis para o consumo.

Com relação ao consumo de leguminosas, é recomendado o consumo diário de 1 porção, sendo o ideal consumir feijão com arroz, na proporção de 1 para 2 partes. O consumo de leguminosas deve garantir cerca de $5 \%$ do total de energia diária (BRASIL, 2008). Na Ilha de Cotijuba nota-se, através da avaliação da frequência alimentar dos entrevistados, que o consumo de feijão ocorre, na maioria das vezes, diariamente juntamente com o arroz. Desta forma, estando de acordo com o recomendado com base nas diretrizes do Ministério da Saúde.

Leite e derivados, principais fontes de cálcio na alimentação, e carnes, aves, peixes e ovos fazem parte de uma alimentação nutritiva que contribui para a saúde e para o crescimento saudável de crianças. É recomendado o consumo diário de 3 porções de leite e derivados e 1 porção de carnes, peixes ou ovos (BRASIL, 2008). Nesta pesquisa, observa-se um consumo elevado de leite e derivados, porém um consumo baixo de carnes, peixes, aves e ovos, mas é importante lembrar o consumo elevado de charque, sabe-se que o charque é uma proteína animal que deve ter o consumo moderado devido ao alto teor de gorduras saturadas bem como de sal, que aumentam o risco de desenvolvimento da obesidade e de alguns tipos de doenças como as cardíacas e alguns tipos de câncer.

A contribuição de gorduras e óleos, de todas as fontes, não deve ultrapassar os limites de $15 \%$ a $30 \%$ da energia total da alimentação diária (BRASIL, 2008). Na Ilha 
em estudo, o grupo dos açúcares, doces, óleos e gorduras apresentou nível baixo de consumo que vai de acordo com as recomendações do Ministério da Saúde, porém os alimentos industrializados apresentaram índices elevados de consumo.

\section{Procedência dos alimentos}

A procedência dos alimentos consumidos pelos moradores da ilha de Cotijuba foi avaliada utilizando as variáveis: não adquire, compra, agricultura, pesca, extrativismo e criação doméstica, a fim de verificar a disponibilidade de alimentos na ilha. Os resultados estão representados na figura 3. Em se tratando do grupo dos pães, massas, farinhas e arroz, foi observado que são adquiridos em sua maioria $(90,8 \%)$ através da compra.

Com relação ao grupo das frutas, dentre as 16 frutas pesquisadas, observou-se que 31,25\% do total (açaí, manga, acerola, cupuaçu e taperebá) são adquiridas através da agricultura ou extrativismo. Em relação às demais frutas (abacate, abacaxi, bacuri, caju, carambola banana, laranja, mamão, goiaba, jaca e jambo), a população possui o hábito de compra-las o que equivale a $68,75 \%$ das frutas pesquisadas.

Figura 3 - Procedência dos alimentos consumidos dos moradores de Cotijuba

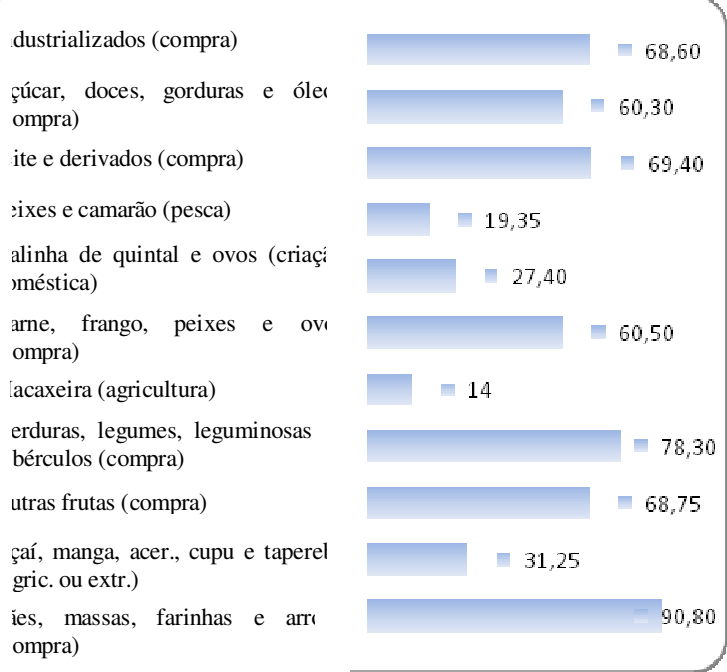

Fonte: Pesquisa de campo 2011

Analisando o grupo dos legumes, verduras, leguminosas e tubérculos, foram pesquisados 14 tipos (alface, batata, beterraba, cebolinha, coentro, cenoura, chuchu, couve, feijão, maxixe, macaxeira, pepino, pimentinha verde e tomate), cuja a grande maioria $(78,3 \%)$ é adquirida através da compra. Destaque para a macaxeira onde uma pequena parcela da população (14\%), ainda utiliza a agricultura como forma de aquisição deste tubérculo.

No grupo das carnes, frangos, peixes e ovos, pode-se constatar, analisando os resultados, que $60,50 \%$ dos moradores pesquisados adquirem-nos através da compra. Destaca-se neste grupo a galinha de quintal e ovos, onde $27,40 \%$ dos entrevistados dispõem de criação doméstica para a aquisição dos mesmos. Uma pequena parcela dos moradores pesquisados $(19,35 \%)$ utiliza a pesca como forma de obtenção de peixes e camarão.

O grupo de leite e derivados; açúcares, doces, gorduras e óleos; e alimentos 
industrializados, apresentaram 69,4\%; 60,3\% e $68,6 \%$ respectivamente, para a aquisição através da compra.

Com relação às frutas consumidas em Cotijuba, segundo relatos dos moradores entrevistados, o consumo maior se dá em períodos de safra. Contudo, no quadro 1 é demonstrado o período de safra das frutas regionais pesquisadas neste estudo. No entanto, analisando estes períodos de safra nota-se que ocorrem em épocas variadas. Desta forma, provavelmente sempre haverá um ou dois tipos de frutas disponíveis na ilha durante todo o ano.

Quadro 1 - Relação do Período de Safra das

Frutas Regionais

\begin{tabular}{|c|c|}
\hline Frutas & Safra \\
\hline Açaí & Julho - Setembro \\
\hline Manga & Outubro- Março \\
\hline Acerola & Dezembro-Março \\
\hline Cupuaçu & Março e Junho \\
\hline Taperebá & Ano todo \\
\hline Abacate & Novembro e Janeiro \\
\hline Abacaxi & Janeiro - Abril \\
\hline Bacuri & Outubro - Novembro \\
\hline Caju & Junho - Dezembro \\
\hline Carambola & Ano todo \\
\hline Banana & Maio - Agosto \\
\hline Laranja & Agosto - Janeiro \\
\hline Mamão & Abril - Junho/Nov. - Fev. \\
\hline Goiaba & Janeiro - Março \\
\hline Jaca & Janeiro - Maio \\
\hline Jambo & \\
\hline
\end{tabular}

Fonte: Pesquisa de campo 2011

A partir da análise dos resultados da procedência, notou-se que a forma predominante dos moradores da ilha de Cotijuba de adquirir seus alimentos é através da compra, até mesmo em relação a determinados grupos de alimentos que, em comunidades rurais, são típicos da agricultura e extrativismo (verduras, legumes e frutas). Este cenário encontrado vai de encontro com o que Murrieta (2001) define como o perfil regional de comunidades rurais amazônicas, que é caracterizado por sistema de subsistência e dominados pela pesca, caça, agricultura de corte e queima, extração e comercialização de produtos florestais e engajamento crescente em atividades assalariadas.

Silva (2004) preconiza que essas comunidades apresentam, ainda, uma multiplicidade de itens alimentares secundários altamente sazonais e uma crescente dependência de produtos de mercado, principalmente os industrializados provenientes de outras regiões e essa tendência parecem vir acompanhados, na maioria dos casos, pelo abandono de práticas de subsistência tradicionais e perda total ou parcial da auto-suficiência na produção de alimentos. No caso de Cotijuba percebe-se essa perda devido às atividades cada vez mais voltadas ao turismo e a crescente abertura de novas "vendinhas" que comercializam esses produtos industrializados.

Fazendo um comparativo com outras comunidades estudadas por Murrieta (2008), as unidades domésticas mostram-se bastante vinculadas com a agricultura enquanto que em 
Cotijuba, percebe-se uma unidade familiar na maioria dos casos vinculados a compra.

Com relação à disponibilidade dos alimentos dentro da ilha, observou-se que uma minoria dos moradores pesquisados adquire determinados alimentos na própria ilha sem precisar deslocar-se para outros distritos como Icoaraci, localizado na região Metropolitana de Belém-Pa, distante cerca de 50 minutos de barco. Estes alimentos, provenientes da ilha são obtidos através da pesca (peixe e camarão), criação doméstica (galinha e ovos), agricultura e extrativismo onde as frutas que mais se destacam nesse tipo de atividade são açaí, manga, acerola, cupuaçu e taperebá e em relação aos tubérculos temos a macaxeira em que uma pequena parcela da população ainda cultiva este alimento.

Pereira (2007) conceitua os quintais ou sítios implantados pelos agricultores familiares tradicionais que constituem a área ao redor da casa do produtor, onde são cultivadas árvores frutíferas, grãos, hortaliças, plantas medicinais e ornamentais e criação de animais, tem como finalidade principal a complementação da produção obtida em outras áreas de produção da propriedade, como a roça, a criação de animais, a floresta e as capoeiras melhoradas como quintal agroflorestal. Na ilha de Cotijuba, a minoria dos habitantes, que ainda advém seus produtos da agricultura, podem ser enquadradas como utilizando este conceito de quintal.

\section{CONCLUSÃO}

A Ilha de Cotijuba é uma comunidade que possui famílias de baixa renda, associado ao baixo nível de escolaridade e residências relativamente pequenas que abrigam um número elevado de pessoas, que destinam o lixo doméstico à queima e realizam o tratamento da água para o consumo, porém muitas vezes de maneira inadequada.

O perfil alimentar destas famílias é bem variado com a presença de cereais (arroz), tubérculos (farinha de mandioca), leguminosas (feijão), verduras e frutas (principalmente açaí e manga), com relação às proteínas de origem animal destacaram-se o leite e o charque.

Tais alimentos consumidos pelas famílias da ilha são adquiridos em sua maioria através da compra, porém ainda percebe-se uma pequena parcela de moradores que utilizam a agricultura, extração, criação doméstica e pesca para a obtenção de alguns alimentos.

O hábito alimentar desta comunidade evidencia-se diferenciado de outras comunidades tradicionais amazônicas, onde a base da alimentação é caracterizada pelo binômio peixe e mandioca, baixa diversidade de frutas e legumes, sendo tais produtos provenientes geralmente da exploração dos recursos naturais. 


\section{REFERÊNCIAS}

AGUIAR, G.F. S. Nutrição e adaptação humana em áreas de pesca na Amazônia: sugestões para políticas em saúde. Bol. Mus. Para. Emílio Goeldi. Ciências Humanas, Belém, v. 1, nº 2. São Paulo, 2006.

BRASIL. Guia alimentar para a população brasileira: Promovendo a alimentação saudável. Brasilia, 2008. Disponível em: < http://bvsms.saude.gov.br/bvs/publicacoes/gui a_alimentar_populacao_brasileira.pdf $>$. Acesso em 29 de mai. 2011.

CANTO, O. Cartografia dos Ambientes e das Populações Amazônicas - Projeto CAPAM.

Belém, 2004. Disponível em: < http://projetocapam.blogspot.com/2008/09/ilh a-de-cotijuba-possui-15-quilmetros.html >. Acesso em: 15 out. 2010.

COSTA, R. C. et al. Diagnóstico da salubridade ambiental na ilha de Cotijuba Belém-PA. Centro Federal de Educação Tecnológica do Pará CEFET-PA, Belém, 2007.

DIEGUES, A. C.; ARRUDA, R. S. V. Saberes tradicionais e biodiversidade no Brasil. Brasília: Ministério do Meio Ambiente. São Paulo, 2001.

FUNASA. Resumo de conhecimento geográfico, relação de localidades. Sistema de Referência Geográfico. Belém, 2010.

MARTINS, A. K.A. A Ruralidade da Ilha de Cotijuba: Um olhar etnográfico. Lato \& Sensu, Belém v.4, nº 2, p. 6, 2003.

MURRIETA, R. S. S. Dialética do sabor: alimentação, ecologia e vida cotidiana. Revista de Antropologia, São Paulo v. 44 n², 2001.

MURRIETA, R.S.S. et al. Consumo alimentar e ecologia de populações ribeirinhas em dois ecossistemas amazônicos: um estudo comparativo. Revista de Nutrição, Campinas, v.21, 2008.

FRAXE, T de J. F.; PEREIRA, H. dos S.; WITKOSKI, A. C.. O ser da Amazônia: Identidade e Invisibilidade. Manaus: Universidade Federal do Amazonas, 2008.

PEREIRA, H.S. A agricultura familiar: principal fonte de desenvolvimento socioeconômico e cultural das comunidades da área focal do projeto piatam. Socioeco, 02 vol., 2007.

SICHIERI, R. Estudo de validação do questionário de frequência de consumo de alimentos. In: SICHIERI, R. (org.).

Epidemiologia da Obesidade. Rio de Janeiro: EdUERJ, 1998b.

SILVA, A.L.Uso de recursos por ribeirinhos no médio Rio Negro. In: Ecologia de pescadores da Mata Atlântica e da Amazônia. São Paulo: Hucitec; 2004.

SILVA, A.L. Comida de Gente: preferências e tabus alimentares entre os ribeirinhos do Médio Rio Negro (Amazonas, Brasil). Revista de Antropologia, São Paulo, v. 50 nº 1, 2007. Organização Mundial de Saúde [OMS]. Programa Epi-Info. Versão 6.04d. [s.1 : s.n.], 2000. 